\title{
$\mathrm{PH} 105$ reseñas
}

\section{Carmen Laffón: catálogo razonado}

Sevilla: Consejería de Cultura y Patrimonio Histórico: Fundación Cajasol, 2020
Este catálogo razonado es el fruto de una exhaustiva investigación que llevó al profesor Juan Bosco Díaz-Urmeneta, junto a un gran equipo de profesionales, a entrar en lo más profundo de la obra de Carmen Laffón. Por lo tanto, representa un riguroso y minucioso estudio dirigido a reunir, catalogar y publicar la evolución y trayectoria de esta artista sevillana, fallecida en noviembre de 2021.

Juan Bosco Díaz-Urmeneta, quien también falleció en 2021, logró reunir el universo artístico de Carmen Laffón: una vida dedicada a la pintura y al arte a través de más de 1.400 obras realizadas desde 1950 a 2020. En su producción es posible descubrir un hilo común, una mirada que imprime dignidad a los objetos, los paisajes y las personas. En la obra de Carmen Laffón los temas que dominan son el paisaje (el Guadalquivir, Doñana, la ciudad, su esquinas, etc.), el bodegón y el retrato, los cuales practica desde la pintura, el dibujo y la escultura.

Para la realización de este catálogo el autor ha estructurado el volumen en trece temas principales, seguidos de un anexo, que es una prolongación del capítulo Paisajes, y que lleva como título Las horas y los días. Este anejo incluye además "más de cuarenta piezas al pastel que recogen, bajo luces, nubes y grabados de humedad diferentes, al Guadalquivir a su paso entre Sanlúcar y Doñana" (p. 14).

En el primer capítulo, Cartas, el autor relata de manera coherente la importancia de la carta y el libro al interior de la obra de arte. Para ello utiliza ocho obras realizadas por Laffón entre 1960 y 1970, las cuales, según el autor, "permiten trazar un primer compendio de la evolución de sus primeros años" (p. 17). Continúa con Homenajes, un capítulo donde el autor se centra especialmente en las obras que Laffón dedicada a personas e instituciones que han tenido relevancia durante su vida, como Zabaleta, Mozart y Murube, entre otros.

En el siguiente capítulo, Figuras, Díaz-Urmeneta expone la evolución artística de la pintora sevillana a través de su paso por Roma, donde presenta la conexión entre la tradición del quattrocento y la influencia de Ortega Muñoz, y París, donde Laffón otorga a la figura, al objeto o al paisaje la dignidad de la existencia. En este capítulo, el autor da importancia en particular al ciclo de Marcelina, una serie de pinturas que muestran a una antigua muñeca que despierta en la artista "recuerdos de la infancia y a la vez inquietan a la conciencia adulta" (p. 54). El autor continúa su análisis dando una particular

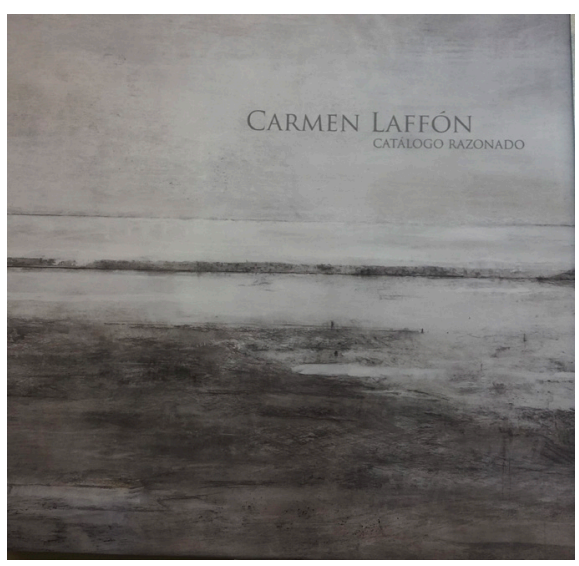


importancia a las Flores. Este cuarto capítulo presenta el momento de madurez de la artista: "las flores de Carmen Laffón se limitan a estar ahí y ofrecer o reabrir un modesto enclave a la sensualidad. Son un encuentro entre la sencillez y la sensualidad" (p. 67). El autor prosigue con un tema dedicado a los Jardines ya que, como es conocido, la artista frecuentaba constantemente las calles sevillanas. El interior del capítulo se divide en pinturas que realiza en el Generalife (Granada), aquellas en las cuales la ventana es protagonista; en La Jara (Sanlúcar de Barrameda) y algunos estudios de jardines creados por la artista. Con esto el autor nos recuerda que estas obras nos invitan a ejercitar la imaginación más allá de los límites materiales de la pintura. Aunque en Andalucía es frecuente la convivencia del huerto y el jardín para el autor "el tiempo del huerto es diferente al del jardín" (p. 140). Es por ello que dedica un capítulo al Huerto, en el que reúne una gran cantidad de obras, divididas en pintura, dibujo y escultura, donde se ocupa de la viña y la parra "pues las obras más ambiciosas de Carmen Laffón son sin duda en ciclo de La viña y la Parra en otoño" (p. 148).

El siguiente capítulo, Del interior (género artístico) al lugar (enclave antropológico), el autor muestra la genialidad de la artista al ejercitar este doble espacio típico de la Modernidad, a través de una serie de obras donde se reflexiona sobre el espacio de trabajo del artista. En tal espacio la artista "no busca reproducir la literalidad del aquel estudio, sino reconstruir su memoria, inscrita en la trama espacial del mismo" (p. 213). Continúa en el siguiente capítulo analizando los Objetos al uso, aquellos objetos que por sí solos pueden definir un cuadro, como por ejemplo, en el caso de Laffón, objetos domésticos, canastas con ropa blanca, máquinas de coser y receptores de radio entre otros. De esta forma separa la tradición del bodegón y entra en la vida social y en la crónica de las costumbres.

Los dos siguientes capítulos, Bodegones y Paisajes, son los más extensos en cuanto a producción artística se refiere. En el primero el autor empieza explicando el valor de indudable atractivo que este tipo de obra puede generar al artista y al que observa. Es indudable que en los cuadros de Laffón se busca un contraste entre la sólida presencia y el vigor de la luz, generando un encuentro e impulsando nuestra atención. Por otro lado, el segundo representa uno de los temas más estudiados de la artista. En la obra de Laffón no se puede dejar de lado el paisaje, aquella vivencia auténtica del lugar, a través de la experiencia sensible, generando un vínculo con este. Además el autor anexa más de setenta piezas que representan el Coto de Doñana visto desde Sanlúcar, realizados a lo largo de su carrera artística.

El catálogo continúa con un capítulo dedicado a los Niños, obras que llaman la atención por la delicadeza con la que Laffón representa este tipo de obras. Y con los Retratos, capítulo en el que el autor explica la diferencia entre los retratos pintados entre el 1955 y 1961, donde se observa la utilización de un 
punto de vista más frontal que la profundidad, y cómo a partir de 1962 su obra cambia mostrando "afán por dar a la figura la entereza de lo que he llamado verdad de su existencia” (p. 564). Para finalizar el catálogo, el último capítulo se ha dedicado a los Carteles. El que da una mirada diferente de la Semana Santa, el cartel de toros para la Maestranza de Caballería y el cartel para las Carreras de caballos en las playas de Sanlúcar, todos ellos caracterizados por el respeto hacia la imagen social que generan dichos acontecimientos.

En síntesis, esta compleja obra reúne la brillante carrera artística de Carmen Laffón, desde su origen hasta las obras expuestas en septiembre del 2020 en el Centro Andaluz de Arte Contemporáneo, con el proyecto denominado La sal, paisajes de las salinas de Bonanza en Sanlúcar de Barrameda. A través de un itinerario trazado por Juan Bosco Díaz-Urmeneta en el que no solamente se pone en relieve el valor de la obra, sino la atenta descripción de cada concepto u objeto que forma parte de ella.

César Augusto Suárez Cajamarca | Doctorando en Patrimonio Cultural de la Iglesia, Pontificia Universidad Gregoriana de Roma

URL de la contribución <www.iaph.es/revistaph/index.php/revistaph/article/view/5034> 